\title{
Serum calcium is independently associated with insulin sensitivity measured with euglycaemic-hyperinsulinaemic clamp in a community-based cohort
}

\author{
E. Hagström • P. Hellman • E. Lundgren $•$ L. Lind • \\ J. Ärnlöv
}

Received: 27 July 2006 / Accepted: 17 September 2006 / Published online: 20 December 2006

(C) Springer-Verlag 2006

\begin{abstract}
Aims/hypothesis Diabetes mellitus type 2 is associated with altered calcium metabolism. Moreover, in diseases with supranormal serum calcium levels, such as primary hyperparathyroidism, the prevalence of diabetes is increased. Relatively little is known about the relationship between serum calcium concentration and the underlying causes of diabetes - insulin resistance and defective insulin secretionin the normocalcaemic general population.

Materials and methods We investigated associations between serum calcium concentration and insulin sensitivity and secretion in a population-based cohort of elderly men (Uppsala Longitudinal Study of Adult Men, $n=961$ ). Insulin sensitivity index $(\mathrm{M} / \mathrm{I}$; glucose disposal rate $[\mathrm{M}]$ divided by mean insulin concentration [I]) was assessed using euglycaemic-hyperinsulinaemic clamp, and insulin secretion was estimated from the early insulin response (EIR) during an OGTT.
\end{abstract}

\footnotetext{
Electronic supplementary material Supplementary material is available in the online version of this article at http://dx.doi.org/ $10.1007 / \mathrm{s} 00125-006-0532-9$ and is accessible to authorised users.

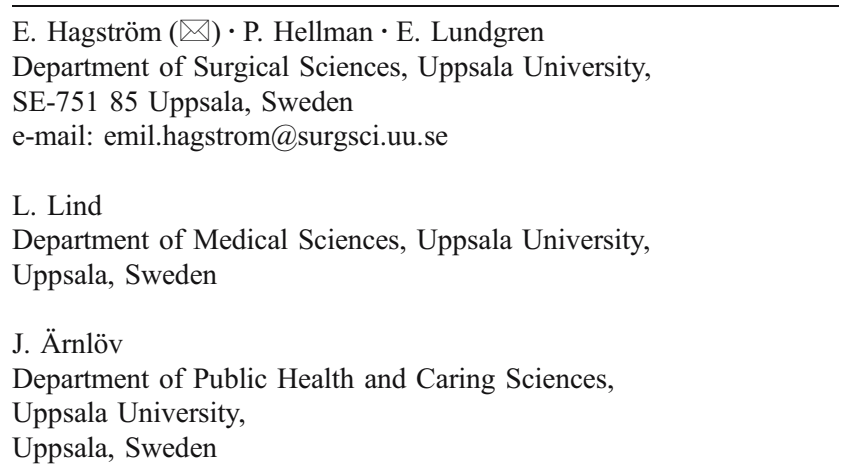

Results In a multivariable linear regression model adjusting for BMI, physical activity, smoking, consumption of tea, alcohol, coffee and dietary calcium, serum phosphate and serum creatinine, $1 \mathrm{SD}$ increase in serum calcium was associated with $0.17 \mathrm{mg} \mathrm{kg}^{-1} \mathrm{~min}^{-1}(\mathrm{mU} / 1)^{-1} \times 100$ $\left(0.024 \mathrm{mg} \mathrm{kg}^{-1} \mathrm{~min}^{-1}[\mathrm{pmol} / 1]^{-1} \times 100\right)$ decrease in $\mathrm{M} / \mathrm{I}$ $(p=0.01)$. The results remained robust in individuals with normal fasting glucose, normal glucose tolerance and serum calcium within the normal range $(n=413$, regression coefficient for $1 \mathrm{SD}$ increase $-0.45, p=0.001)$. Serum calcium was not associated with EIR. Dietary intake of calcium was not independently associated with insulin sensitivity or EIR.

Conclusion/interpretation Our data support the notion that endogenous calcium may be involved early in the development of diabetes and that this effect is mediated mainly through effects on insulin sensitivity rather than defective insulin secretion. Dietary intake of calcium does not seem to influence insulin sensitivity.

Keywords Calcium - Diet - Early insulin response ·

Euglycaemic-hyperinsulinaemic clamp · Insulin sensitivity

\begin{tabular}{ll}
\multicolumn{2}{l}{ Abbreviations } \\
EIR & early insulin response \\
HOMA & homeostasis model assessment \\
M & glucose disposal rate \\
M/I & insulin sensitivity index \\
25-OH & 25-hydroxycholecalciferol \\
vitamin $D_{3}$ & \\
PTH & parathyroid hormone \\
ULSAM & Uppsala Longitudinal Study of Adult Men
\end{tabular}




\section{Introduction}

In population-based studies, non-insulin dependent diabetes mellitus (NIDDM) and prediabetic states, such as IFG and IGT, are strongly associated with increased cardiovascular morbidity and mortality from cardiovascular causes [1,2]. Previous reports have also shown that patients with diabetes have elevated serum levels of calcium compared with nondiabetic individuals [3-5], and that the serum levels of calcium increase even further with decreasing metabolic control [3, 4]. Moreover, in diseases with supranormal levels of serum calcium, such as primary hyperparathyroidism, there is a two- to fourfold higher prevalence of NIDDM and prediabetic states than in the general population [4, 6, 7]. Less is known about the relationship between serum calcium concentration and the two underlying causes of diabetes: insulin sensitivity and defective insulin secretion.

Recent experimental data suggest a close relationship between calcium and both insulin sensitivity and secretion through intra- and extracellular mechanisms $[8,9]$. Intracellular calcium disturbances have been suggested as the factor linking the wide range of abnormalities of the metabolic syndrome, such as hypertension, insulin resistance and obesity $[8,9]$. A few previous epidemiological investigations have explored the associations between extracellular serum levels of calcium, insulin sensitivity and secretion [10-13]. However, previous studies have been limited by the use of surrogate markers of insulin sensitivity and secretion [10-13]. All previous epidemiological studies have included subjects with diabetes or IFG and IGT [10-13], making it difficult to evaluate the independent relationship of serum calcium with the underlying causes of pathologically increased levels of glucose. Furthermore, all previous studies have included individuals with supra- and subnormal levels of calcium [10-13] and our knowledge of the relationship between serum calcium within the normal range and insulin sensitivity and secretion is limited.

Thus, a few questions about the association between serum levels of calcium and insulin sensitivity and secretion are unanswered. Is serum calcium associated with insulin sensitivity (as measured by the gold standard clamp method) and insulin secretion independently of lifestyle factors in the general population? If so, is serum calcium also associated with insulin sensitivity and secretion after the exclusion of individuals with abnormal glucose levels? Furthermore, is this relationship consistent in individuals with serum calcium in the normal range? To answer these questions, we investigated the relationships between the serum levels of calcium and insulin sensitivity, evaluated using the hyperinsulinaemic-euglycaemic clamp, and secretion, evaluated as the early insulin response (EIR) during an OGTT, in a population-based cohort of elderly men with emphasis on subgroup analyses in individuals with normal fasting glucose, normal glucose tolerance and normal serum calcium. As a secondary aim, we also investigated the association between dietary intake of calcium and insulin sensitivity and secretion, as previous studies have suggested that higher dietary intake of calcium is associated with a lower risk of developing diabetes [14].

\section{Subjects and methods}

\section{Study sample}

The design and selection criteria of the Uppsala Longitudinal Study of Adult Men (ULSAM) [15] have been described previously [16]. In our study, 1,221 individuals, 70 years of age, were evaluated at the second follow-up investigation. We excluded 260 men for the following reasons: unavailable albumin-corrected serum calcium data $(n=45)$; unavailable euglycaemic-hyperinsulinaemic clamp data $(n=59)$; and missing covariates $(n=156)$. Thus, our study sample was 961 individuals. Of these, 960 had available early insulin response data. All participants gave written informed consent and the Ethics Committee of Uppsala University approved the study protocol.

\section{Clinical and biochemical evaluation}

Examinations performed included euglycaemic-hyperinsulinaemic clamp, OGTT and assessment of biochemical variables. Laboratory analyses were performed as follows. Serum calcium was measured spectrophotometrically with a compleximetric method using $o$-cresolphthalein (normal range $2.20-2.60 \mathrm{mmol} / \mathrm{l}$ ). Serum albumin was measured by spectrophotometry using bromine cresol green (normal range 37-48 g/l). Albumin-corrected serum calcium was calculated as: serum calcium $+0.019 \times(46$-plasma albumin). Serum phosphate was measured by spectrophotometry using a compleximetric method with ammonium molybdate (normal range 0.74-1.54 mmol/l). Serum creatinine was measured by spectrophotometry using Jaffe's reaction (normal range 60-106 $\mu \mathrm{mol} / \mathrm{l}$ ). The instruments used for biochemical analysis were Hitachi 717 and 911 (Hitachi Corp., Tokyo, Japan). Plasma glucose was measured by the glucose dehydrogenase method (Gluc-DH; Merck, Darmstadt, Germany). Coffee, tea and alcohol consumption were recorded using a 7-day precoded food diary according to the instructions of a dietician. Daily intakes were calculated using a computer program and the Swedish National Food Administration database (SLV Database, 1990). Participants also reported their leisure-time physical activity on a standardised questionnaire [17]. Coding of 
smoking was based on interview reports performed by a nurse.

Diabetes mellitus was diagnosed as a fasting plasma glucose level $\geq 7.0 \mathrm{mmol} / \mathrm{l}, 2 \mathrm{~h}$ post-load glucose level $\geq 11.1 \mathrm{mmol} / 1$, or by the use of oral hypoglycaemic agents or insulin. IGT was defined as a $2 \mathrm{~h}$ post-load value of 7.8-11 mmol/1. IFG was defined as fasting glucose concentration of 5.6-6.9 mmol/1 [18]. BMI was calculated as body weight/(body height $)^{2}\left(\mathrm{~kg} / \mathrm{m}^{2}\right)$.

Insulin sensitivity and secretion

The euglycaemic-hyperinsulinaemic clamp technique according to DeFronzo [19] was used, with a slight modification to suppress hepatic glucose production [20], for estimation of in vivo sensitivity to insulin. Insulin (Actrapid Human; Novo, Copenhagen, Denmark) was infused in a primary dose for the first $10 \mathrm{~min}$ and then as a continuous infusion (389 pmol/min per $\mathrm{m}^{2}$ body surface area) for $2 \mathrm{~h}$ to maintain steady-state hyperinsulinaemia, achieving a level of about $660 \mathrm{pmol} / \mathrm{l}$. The target plasma glucose level was $5.1 \mathrm{mmol} / 1$, maintained by measuring plasma glucose every $5 \mathrm{~min}$. The glucose infusion rate during the last hour was used as a measure of glucose disposal rate ( $\mathrm{M}$ value). The insulin sensitivity index (M/I ratio) was calculated by dividing $\mathrm{M}$ by the mean insulin concentration (I) during the same period of the clamp. M/I thus represents the amount of glucose metabolised per unit of plasma insulin and is given as $\mathrm{mg} \mathrm{kg}^{-1} \mathrm{~min}^{-1}(\mathrm{mU} / 1)^{-1} \times 100\left(\mathrm{mg} \mathrm{kg}^{-1}\right.$ $\left.\min ^{-1}[\mathrm{pmol} / 1]^{-1} \times 100\right)$. The $\mathrm{CV}$ of the $\mathrm{M}$ value was $12 \%$ and that of the $\mathrm{M} / \mathrm{I}$ value was $14 \%$ on repeated clamp investigations within 30 days in the same individual [21]. The OGTT was performed by measuring the concentrations of plasma glucose and insulin immediately before and $120 \mathrm{~min}$ after ingestion of $75 \mathrm{~g}$ of anhydrous dextrose. The OGTT and the clamp procedure were performed at least 1 week apart. Beta cell function was estimated by the early insulin response (EIR): ([insulin $30 \mathrm{~min}]-\left[\right.$ insulin $\left.\left._{0 \mathrm{~min}}\right]\right) /$ ([glucose 30 min - glucose $\left._{0 \mathrm{~min}}\right]$ ).

\section{Statistical analyses}

All analyses were defined a priori. If necessary, logarithmic transformation was performed to achieve normal distribution. All variables were normally distributed with the exception of EIR. Two-tailed 95\% CIs and $p$ values are given, with $p<0.05$ regarded as significant. Multiple linear regression models were used to assess the relationship between insulin sensitivity and secretion (dependent variables) and the serum levels of calcium (continuous variable). ANOVA and analysis of covariance (ANCOVA) were used to assess the relationship between insulin sensitivity and secretion and the quartiles of serum calcium concentration.
The models used were as follows. Model A was unadjusted. Model B was adjusted for BMI, physical activity, smoking and consumption of tea, alcohol, coffee and dietary intake of calcium. Model $\mathrm{C}$ was as model B but was also adjusted for serum phosphate and serum creatinine. All models evaluating the relationship between EIR and serum calcium were also adjusted for $\mathrm{M} / \mathrm{I}$, as previous studies have shown that EIR does not seem to provide clinically relevant information except when adjusted for insulin sensitivity $[22,23]$. Apart from using the whole cohort $(n=961)$ for our analyses, we also used the following prespecified subgroups: 1, normal fasting glucose and glucose tolerance $(n=442) ; 2$, normal fasting glucose and glucose tolerance and serum calcium in the normal range $(n=413)$.

In exploratory analyses we investigated the association of non-corrected serum calcium with $\mathrm{M} / \mathrm{I}$ in order to exclude the possibility that the association between albumin-corrected calcium concentration and $\mathrm{M} / \mathrm{I}$ was driven by a relation between albumin concentration and $\mathrm{M} / \mathrm{I}$. Other exploratory analyses included the association between serum calcium and other indices of insulin sensitivity, such as the glucose disposal rate (M) and homeostasis model assessment (HOMA) insulin sensitivity. Moreover, we analysed the association between serum calcium and $\mathrm{M} / \mathrm{I}$ in the subgroup with diabetes mellitus, impaired fasting glucose or glucose intolerance $(n=519)$. The associations between dietary calcium and $\mathrm{M} / \mathrm{I}$ and $\mathrm{M}$ were also investigated.

The statistical software package STATA 8.2 (Stata Corp, College Station, TX, USA) was used.

\section{Results}

Clinical baseline characteristics of the study population and for the quartiles of serum calcium concentration are presented in Table 1. In the whole cohort $(n=961)$, three subjects had serum calcium above the normal range $(>2.60 \mathrm{mmol} / \mathrm{l})$ and 58 subjects had serum calcium below the normal range $(<2.20 \mathrm{mmol} / \mathrm{l})$. Median $\mathrm{M} / \mathrm{I}$ in the subjects with hypercalcaemia was $3.59 \pm 1.4 \mathrm{mg} \mathrm{kg} \min ^{-1}(\mathrm{mU} / 1)^{-1} \times 100$ $\left(0.52 \pm 0.20 \mathrm{mg} \mathrm{kg}{ }^{-1} \min ^{-1}[\mathrm{pmol} / 1]^{-1} \times 100\right)$ and median $\mathrm{M} / \mathrm{I}$ in those with hypocalcaemia was $4.7 \pm 2.4 \mathrm{mg} \mathrm{kg}^{-1} \mathrm{~min}^{-1}$ $(\mathrm{mU} / \mathrm{l})^{-1} \times 100\left(0.68 \pm 0.35 \mathrm{mg} \mathrm{kg}^{-1} \mathrm{~min}^{-1}[\mathrm{pmol} / \mathrm{l}]^{-1} \times 100\right)$.

Insulin sensitivity

In the linear regression models $\mathrm{B}$ and $\mathrm{C}, 1 \mathrm{SD}$ increase in serum calcium was associated with a decrease of $0.17-$ $0.19 \mathrm{mg} \mathrm{kg}^{-1} \mathrm{~min}^{-1}(\mathrm{mU} / 1)^{-1} \times 100\left(0.024-0.027 \mathrm{mg} \mathrm{kg}^{-1}\right.$ $\left.\min ^{-1}[\mathrm{pmol} / 1]^{-1} \times 100\right)$ in $\mathrm{M} / \mathrm{I}$ in the whole sample $(p<0.01)$ (Table 2). This association remained essentially the same in the subsample with normal glucose and became 
Table 1 Baseline characteristics of the total cohort and for quartiles of serum calcium concentration

\begin{tabular}{|c|c|c|c|c|c|}
\hline Variable & Total cohort & Quartile 1 & Quartile 2 & Quartile 3 & Quartile 4 \\
\hline Age (years) & $71.0 \pm 0.58$ & $71.1 \pm 0.58$ & $71.0 \pm 0.59$ & $70.9 \pm 0.54$ & $70.9 \pm 0.60$ \\
\hline Serum calcium $(\mathrm{mmol} / \mathrm{l})^{\mathrm{a}}$ & $2.33 \pm 0.09$ & $2.22 \pm 0.09$ & $2.31 \pm 0.05$ & $2.36 \pm 0.05$ & $2.44 \pm 0.06$ \\
\hline Serum calcium range $(\mathrm{mmol} / \mathrm{l})^{\mathrm{a}}$ & $1.62-2.85$ & $1.62-2.28$ & $2.29-2.33$ & $2.34-2.39$ & $2.40-2.85$ \\
\hline Serum albumin $(\mathrm{g} / \mathrm{l})$ & $43.1 \pm 2.6$ & $43.7 \pm 2.5$ & $43.6 \pm 2.6$ & $42.8 \pm 2.4$ & $42.4 \pm 2.7$ \\
\hline BMI $\left(\mathrm{kg} / \mathrm{m}^{2}\right)$ & $26.2 \pm 3.4$ & $26.5 \pm 3.2$ & $26.4 \pm 3.5$ & $25.9 \pm 3.2$ & $26.0 \pm 3.5$ \\
\hline Fasting plasma glucose $(\mathrm{mmol} / \mathrm{l})$ & $5.75 \pm 1.4$ & $5.71 \pm 1.4$ & $5.76 \pm 1.5$ & $5.84 \pm 1.5$ & $5.68 \pm 1.2$ \\
\hline Fasting serum insulin $(\mathrm{pmol} / \mathrm{l})$ & $88.2 \pm 49$ & $88.2 \pm 51$ & $86.1 \pm 48$ & $83.3 \pm 47$ & $90.3 \pm 50$ \\
\hline \multicolumn{6}{|l|}{$\mathrm{M} / \mathrm{I}$} \\
\hline $\left.\mathrm{mg} \mathrm{kg}^{-1} \min ^{-1}(\mathrm{mU} / \mathrm{l})^{-1} \times 100\right)$ & $5.06 \pm 2.5$ & $5.11 \pm 2.4$ & $5.14 \pm 2.6$ & $5.20 \pm 2.5$ & $4.79 \pm 2.3$ \\
\hline $\left.\mathrm{mg} \mathrm{kg}^{-1} \min ^{-1}(\mathrm{pmol} / 1)^{-1} \times 100\right)$ & $0.73 \pm 0.36$ & $0.74 \pm 0.35$ & $0.74 \pm 0.37$ & $0.75 \pm 0.36$ & $0.69 \pm 0.33$ \\
\hline $\mathrm{M}\left(\mathrm{mg} \min ^{-1} \mathrm{~kg}^{-1}\right)$ & $5.20 \pm 2.1$ & $5.22 \pm 2.0$ & $5.21 \pm 2.1$ & $5.31 \pm 2.1$ & $5.04 \pm 2.1$ \\
\hline HOMA insulin sensitivity & $3.34 \pm 2.4$ & $3.36 \pm 2.6$ & $3.27 \pm 2.3$ & $3.18 \pm 2.3$ & $3.54 \pm 2.3$ \\
\hline EIR & $13.7 \pm 11$ & $13.2 \pm 11$ & $13.3 \pm 11$ & $13.6 \pm 11$ & $14.7 \pm 11$ \\
\hline Serum creatinine $(\mu \mathrm{mol} / 1)$ & $93.7 \pm 14$ & $92.4 \pm 14$ & $92.2 \pm 12$ & $94.1 \pm 13$ & $96.1 \pm 15$ \\
\hline Serum phosphate (mmol/l) & $0.96 \pm 0.21$ & $0.94 \pm 0.2$ & $0.95 \pm 0.2$ & $0.97 \pm 0.2$ & $0.99 \pm 0.3$ \\
\hline Coffee (cups per day) & $3.36 \pm 1.6$ & $3.3 \pm 1.6$ & $3.3 \pm 1.5$ & $3.3 \pm 1.7$ & $3.5 \pm 1.7$ \\
\hline Tea (cups per day) & $0.67 \pm 0.7$ & $0.68 \pm 0.7$ & $0.70 \pm 0.7$ & $0.70 \pm 0.6$ & $0.60 \pm 0.6$ \\
\hline Dietary calcium (mg/day) & $965 \pm 337$ & $975 \pm 351$ & $981 \pm 325$ & $961 \pm 326$ & $943 \pm 347$ \\
\hline Alcohol (g/day) & $1.08 \pm 0.62$ & $1.11 \pm 0.61$ & $1.06 \pm 0.62$ & $1.11 \pm 0.63$ & $1.05 \pm 0.61$ \\
\hline \multicolumn{6}{|l|}{ Physical activity level: $n(\%)$} \\
\hline Sedentary & $31(3.23)$ & $5(2.07)$ & $7(3.0)$ & $8(3.17)$ & $10(4.48)$ \\
\hline Moderate & $326(33.9)$ & $87(36.1)$ & $78(33.5)$ & $86(34.1)$ & $72(32.3)$ \\
\hline Regular & $546(57.1)$ & $139(57.7)$ & $135(57.9)$ & $139(55.2)$ & $130(58,3)$ \\
\hline Athletic & $55(5.72)$ & $10(4.15)$ & $13(5.6)$ & $19(7.54)$ & $11(4.9)$ \\
\hline Smoking: $n(\%)$ & $196(20.4)$ & $48(19.9)$ & $43(18.5)$ & $44(17.5)$ & $60(26.9)$ \\
\hline
\end{tabular}

Data are mean $\pm \mathrm{SD}$

$n=961$

${ }^{\mathrm{a}}$ Albumin-corrected serum calcium

even stronger in the subsample with serum calcium concentration within the normal range.

In the analyses of quartiles of serum calcium in the whole cohort, the subjects in the lowest quartile of calcium had significantly higher insulin sensitivity than the subjects in quartile 4 in all models (models $\mathrm{A}-\mathrm{C}$; Table 3 ). This relation became even stronger in the subsample with normal glucose and glucose tolerance, and in the subsample with normal glucose, glucose tolerance and normal serum calcium.

The association between serum calcium and the glucose disposal rate $(\mathrm{M})$ was essentially the same as the association between serum calcium and $\mathrm{M} / \mathrm{I}$ (data not shown). Furthermore, the results remained essentially the same when using non-albumin-corrected serum calcium concen-

Table 2 Linear regression analysis of M/I, EIR and serum levels of calcium in different subgroups

\begin{tabular}{|c|c|c|c|c|c|c|c|}
\hline \multirow[t]{2}{*}{ Regression analysis } & \multirow[t]{2}{*}{ Model } & \multicolumn{2}{|c|}{ Total cohort $(n=961)$} & \multicolumn{2}{|c|}{$\begin{array}{l}\text { Normal fasting glucose } \\
\text { and glucose tolerance }(n=442)\end{array}$} & \multicolumn{2}{|c|}{$\begin{array}{l}\text { Normal fasting glucose, glucose } \\
\text { tolerance and serum calcium }(n=413)\end{array}$} \\
\hline & & $\beta$ & $p$ value & $\beta$ & $p$ value & $\beta$ & $p$ value \\
\hline \multirow[t]{3}{*}{ Insulin sensitivity index $(\mathrm{M} / \mathrm{I})$} & A & -0.10 & 0.196 & -0.07 & 0.48 & -0.34 & 0.024 \\
\hline & $\mathrm{B}$ & -0.19 & 0.004 & -0.19 & 0.033 & -0.50 & $<0.001$ \\
\hline & $\mathrm{C}$ & -0.17 & 0.01 & -0.16 & 0.08 & -0.45 & 0.001 \\
\hline \multirow[t]{3}{*}{ Insulin secretion (EIR) } & A & 0.015 & 0.57 & -0.01 & 0.72 & -0.03 & 0.50 \\
\hline & $\mathrm{B}$ & 0.019 & 0.47 & -0.006 & 0.86 & -0.02 & 0.70 \\
\hline & $\mathrm{C}$ & 0.01 & 0.70 & -0.006 & 0.84 & -0.02 & 0.66 \\
\hline
\end{tabular}

Data are regression coefficients for 1 SD increase of serum calcium

Model A is unadjusted; model B is adjusted for BMI, physical activity, smoking and consumption of tea, alcohol, coffee and dietary calcium; model $\mathrm{C}$ is adjusted for BMI, physical activity, smoking, consumption of tea, alcohol, coffee and dietary calcium, serum phosphate and creatinine. All models evaluating the relationship between EIR and serum calcium were also adjusted for M/I. 
Table $3 \mathrm{M} / \mathrm{I}$ and EIR in different quartiles of serum calcium in different subgroups

\begin{tabular}{|c|c|c|c|c|c|c|c|}
\hline & \multirow[t]{2}{*}{ Quartile } & \multicolumn{2}{|c|}{ Total cohort $(n=961)$} & \multicolumn{2}{|c|}{$\begin{array}{l}\text { Normal fasting glucose } \\
\text { and glucose tolerance }(n=442)\end{array}$} & \multicolumn{2}{|c|}{$\begin{array}{l}\text { Normal fasting glucose, glucose } \\
\text { tolerance and serum calcium }(n=413)\end{array}$} \\
\hline & & $\beta$ & $p$ value & $\beta$ & $p$ value & $\beta$ & $p$ value \\
\hline \multicolumn{8}{|c|}{ Insulin sensitivity index (M/I) } \\
\hline \multirow{4}{*}{ Model A } & $1^{\mathrm{a}}$ & 1 & & 1 & & 1 & \\
\hline & 2 & -0.02 & 0.9 & 0.14 & 0.66 & -0.18 & 0.61 \\
\hline & 3 & 0.11 & 0.51 & 0.19 & 0.55 & -0.13 & 0.71 \\
\hline & 4 & -0.44 & 0.05 & -0.61 & 0.057 & -0.92 & 0.008 \\
\hline \multirow[t]{4}{*}{ Model B } & $1^{\mathrm{a}}$ & 1 & & 1 & & 1 & \\
\hline & 2 & -0.052 & 0.78 & -0.16 & 0.56 & -0.44 & 0.14 \\
\hline & 3 & -0.17 & 0.33 & -0.31 & 0.26 & -0.58 & 0.049 \\
\hline & 4 & -0.60 & 0.001 & -0.88 & 0.002 & -1.2 & $<0.001$ \\
\hline \multirow[t]{4}{*}{ Model C } & $1^{\mathrm{a}}$ & 1 & & 1 & & 1 & \\
\hline & 2 & -0.053 & 0.77 & -0.13 & 0.64 & -0.41 & 0.16 \\
\hline & 3 & -0.16 & 0.38 & -0.27 & 0.32 & -0.54 & 0.062 \\
\hline & 4 & -0.56 & 0.003 & -0.75 & 0.007 & -1.0 & 0.001 \\
\hline \multicolumn{8}{|c|}{ Insulin secretion (EIR) } \\
\hline \multirow[t]{4}{*}{ Model A } & $1^{\mathrm{a}}$ & 1 & & 1 & & 1 & \\
\hline & 2 & 0.003 & 0.97 & -0.08 & 0.41 & -0.13 & 0.22 \\
\hline & 3 & -0.010 & 0.90 & 0.08 & 0.41 & 0.03 & 0.78 \\
\hline & 4 & 0.011 & 0.14 & -0.04 & 0.70 & -0.08 & 0.43 \\
\hline \multirow[t]{4}{*}{ Model B } & $1^{\mathrm{a}}$ & 1 & & 1 & & 1 & \\
\hline & 2 & -0.001 & 0.99 & -0.07 & 0.45 & -0.12 & 0.27 \\
\hline & 3 & -0.001 & 0.99 & 0.09 & 0.35 & 0.05 & 0.62 \\
\hline & 4 & 0.1 & 0.14 & -0.03 & 0.75 & -0.07 & 0.51 \\
\hline \multirow[t]{4}{*}{ Model C } & $1^{\mathrm{a}}$ & 1 & & 1 & & 1 & \\
\hline & 2 & -0.0002 & 1.0 & -0.07 & 0.45 & -0.12 & 0.26 \\
\hline & 3 & -0.01 & 0.88 & 0.09 & 0.35 & 0.05 & 0.62 \\
\hline & 4 & 0.09 & 0.23 & -0.03 & 0.73 & -0.08 & 0.49 \\
\hline
\end{tabular}

Model A is unadjusted; model B is adjusted for BMI, physical activity, creatinine, smoking and consumption of tea, alcohol, coffee and dietary calcium; model C is adjusted for BMI, physical activity, smoking, consumption of tea, alcohol, coffee and dietary calcium, serum phosphate and creatinine. All models evaluating the relationship between EIR and serum calcium were also adjusted for M/I.

${ }^{a}$ Referent

tration in the linear regression models and analyses of quartiles of serum calcium (data not shown).

Serum calcium concentration was borderline associated with HOMA-insulin sensitivity in the multivariable models $\mathrm{B}$ and $\mathrm{C}$ in the full cohort and in the different subsamples (quartile 1 vs quartile 4, regression coefficient $0.25-0.36$, $p=0.04-0.11$ ).

The associations between serum levels of calcium and insulin sensitivity in individuals with abnormal glucose tolerance (impaired fasting glucose, impaired glucose tolerance or diabetes) were similar to those in individuals with normal glucose tolerance, but did not quite reach statistical significance (quartile 1 vs quartile 4 , multivariable regression coefficient $-0.42, p=0.06$ [models B and C]).

Insulin secretion

There were no associations between EIR and serum calcium concentration in any linear regression models or in the analyses of quartiles of serum calcium, in the whole study sample or in any of the subgroups (Table 2 and 3).

Dietary intake of calcium

In the whole cohort, a higher intake of dietary calcium was significantly associated with higher insulin sensitivity (Electronic supplementary material [ESM Tables 1 and 2; model A, regression coefficient for $1 \mathrm{SD}$ increase 0.26, $p=0.001$, regression coefficient for quartile 1 vs quartile $4,0.44, p=0.055)$. No association was found between dietary intake and insulin sensitivity in multivariable models B and C in the whole cohort or in any of the subsamples (ESM Tables 1 and 2). There was no association between EIR and the intake of dietary calcium (data not shown). The association between dietary intake of calcium and the glucose disposal rate (M) was essentially the same as that between dietary calcium and M/I (data not shown). 


\section{Discussion}

Principal findings

Previous experimental studies suggest that calcium may be involved in the regulation of the two underlying causes of diabetes: insulin resistance and defective insulin secretion $[8,9]$. In this community-based cohort of elderly men, increasing levels of serum calcium were associated with decreasing insulin sensitivity, as measured by euglycaemichyperinsulinaemic clamp, independently of lifestyle or dietary factors, serum phosphate or serum creatinine. The results remained consistent even in individuals with normal fasting glucose and glucose tolerance, and in individuals with serum calcium within the normal range. There was no relationship between serum calcium and insulin secretion, as measured by the early insulin response during an OGTT. Moreover, dietary intake of calcium was not associated with $\mathrm{M} / \mathrm{I}$ in multivariable models.

Comparison with the literature

Three previous large-scale studies have investigated the relationship between serum calcium and insulin sensitivity and secretion [10, 12, 13]. In these studies, increasing serum levels of calcium were associated with impaired insulin sensitivity as assessed by fasting insulin or HOMA. Both fasting insulin and HOMA insulin sensitivity are limited as indicators of insulin sensitivity because they are also highly influenced by the individual's beta cell function, i.e. insulin secretion.

To the best of our knowledge, no previous reports have evaluated an association between serum calcium and insulin sensitivity using the euglycaemic-hyperinsulinaemic clamp. Furthermore, no previous studies have investigated this association in individuals with normal glucose and normal levels of serum calcium. The association found between insulin sensitivity and serum calcium in this healthy subgroup suggests that calcium may be involved early in the development of diabetes mellitus and that the association is not driven by a few individuals with supra- or subnormal levels of calcium due to other disorders, such as primary hyperparathyroidism, secondary hyperparathyroidism or malignancies. In the present study, $1 \mathrm{SD}$ increase in serum calcium $(0.09 \mathrm{mmol} / \mathrm{l})$ was associated with a decrease of $\sim 0.5$ units in $\mathrm{M} / \mathrm{I}$ in the multivariable models, which is equivalent to having an excess body weight of $15 \mathrm{~kg}$ at a current mean weight of $100 \mathrm{~kg}$ [24]. This supports the notion that the association between serum calcium and insulin sensitivity could be clinically important. The lack of association between serum calcium and insulin secretion is consistent with prior studies. Sun and co-workers reported that HOMA-estimated beta cell func- tion was negatively associated with calcium in females but not in males [13]. Furthermore, in a previous investigation of the ULSAM cohort when the participants were 50 years old, no association was found between serum calcium and insulin secretion, as estimated by the intravenous glucose tolerance test [12].

In the present study, a higher dietary intake of calcium was related to higher insulin sensitivity only in univariate models in the whole sample, whereas no association was found in any multivariable models or in any subsamples. Thus, our data do not support an independent association between dietary intake of calcium and insulin sensitivity. These findings conflict somewhat with previous studies in women, where dietary and supplemental calcium intake was associated with a lower risk of type 2 diabetes [14] and the metabolic syndrome [25]. It should be noted that in those studies insulin sensitivity was not assessed. Still, the present study and these previous reports indicate that there may be a difference between the effects of endogenous calcium and the effects of exogenous calcium intake. Previous studies show that increasing dietary calcium does not seem to be an important regulator of the serum level of calcium $[26,27]$. As the studies mentioned above included only women and as the present study includes only men, we cannot rule out the possibility of sex differences in the effects of dietary intake of calcium. To resolve this issue, further studies in both men and women are needed.

Possible mechanisms for observed associations

The present association between serum calcium and insulin sensitivity may indicate a causal role of calcium in the regulation of insulin sensitivity. This is supported by previous experimental data $[8,9]$. Increasing intracellular calcium levels have been shown to decrease the effect of insulin in adipocytes due to the reduced number of glucose transporters (GLUT4) and decreased insulin receptor activity [4, 28-31]. In an autopsy study performed in consecutive patients, it was shown that parathyroid adenomas and hyperplasia were far more common than the expected prevalence of overt hypercalcaemia [32]. Therefore, increased PTH levels are likely to be found in a number of elderly subjects within the upper normal distribution of serum calcium levels. PTH could stimulate calcium channels to increase calcium influx, increasing the levels of intracellular calcium [33, 34], thereby influencing insulin sensitivity.

Another possible explanation is that there is no causal relationship between calcium and insulin sensitivity, i.e. that the observed association is confounded by other causal factors related to the serum levels of calcium and insulin sensitivity, such as BMI, physical activity, intake of coffee or alcohol, or excess of oral intake of calcium. Hypophos- 
phataemia and hypercalcaemia are in part associated, and in some previous studies low serum levels of phosphate have also been related to decreased insulin sensitivity [35]. However, our results remained robust even after adjustment for serum phosphate concentration (model C). Other potential confounders are impaired kidney function and secondary hyperparathyroidism, partially adjusted for with creatinine levels. The fact that serum calcium was consistently related to insulin sensitivity independently of these confounders in all subsamples argues against confounding as a sole explanation for our findings. However, it should be pointed out that it is not possible to establish causality in a cross-sectional setting.

It is also possible that our findings could be explained by confounding by potentially important factors that we did not measure, such as PTH and 25-hydroxycholecalciferol (25-OH vitamin $\mathrm{D}_{3}$ ). However, both serum calcium concentration and PTH have previously been associated with 2-h glucose level during an OGTT, with persisting results after adjustment for 25-OH vitamin $\mathrm{D}_{3}$ [10]. Furthermore, in an analysis of 100 individuals, insulin sensitivity as assessed by HOMA was lower in individuals with a high calcium concentration compared with individuals with a low calcium concentration, adjusted for serum $25-\mathrm{OH}$ vitamin $\mathrm{D}_{3}$ and PTH [13]. Both these studies support an independent association between serum calcium and indices of insulin sensitivity, indicating that the association between serum calcium concentration and insulin sensitivity is not mediated only via PTH or vitamin $\mathrm{D}_{3}$.

It is not clear why the relationship between serum calcium and insulin sensitivity appears even stronger after the exclusion of subjects with serum calcium concentration outside the normal range. The fact that mean $\mathrm{M} / \mathrm{I}$ seems to be lower in both hypoand hypercalcaemic individuals could indicate that there is a Ushaped relationship between insulin sensitivity and the full range of serum calcium concentration. As there were only three hypercalcaemic individuals, the exclusion of these subjects is unlikely to cause the increased strength in the association between serum calcium and insulin sensitivity. A possible mechanistic explanation is that increased levels of PTH are also likely to be found in most subjects with hypocalcaemia. Also in this case, PTH might influence intracellular $\mathrm{Ca}^{2+}$ levels and thereby reduce insulin sensitivity. However, we would like to point out that the relationship between serum calcium and insulin sensitivity showed no apparent deviation from linearity when we divided the sample into deciles (data not shown). This is an interesting issue that we were unable to resolve in this study, but which merits further investigation.

\section{Clinical implications}

If there is a causal relationship between calcium levels and insulin sensitivity, it is possible that insulin-resistant indi- viduals and diabetics could benefit from interventions that lower serum calcium. However, longitudinal intervention studies are needed in order to investigate this issue. One potential approach could be to evaluate the metabolic effects of pharmacological treatment with calcimimetics, specific parathyroid calcium receptor agonists, which decrease PTH and calcium levels, apparently without having adverse effects on other tissues [36, 37].

Strengths and limitations

The strengths of this investigation include the large, homogeneous, population-based study population. The ULSAM cohort is the largest cohort in the world examined with euglycaemic-hyperinsulinaemic clamp and as such is particularly suitable for these investigations. Other strengths of the study include the detailed adjustment for lifestyle factors, such as BMI, physical activity, food composition, smoking and alcohol consumption.

A major limitation of the present study is the lack of measurement of PTH and vitamin $\mathrm{D}_{3}$, i.e. we cannot rule out the possibility that the relationship between serum calcium and insulin sensitivity was caused in whole or in part by increasing levels of serum PTH or decreasing levels of 25$\mathrm{OH}$ vitamin $\mathrm{D}_{3}$. As noted above, arguing against this are prior studies in which relationships between serum calcium and insulin sensitivity or glucose tolerance persisted also after adjusting for levels of $\mathrm{PTH}$ and $25-\mathrm{OH}$ vitamin $\mathrm{D}_{3}[10$, 13]. Other limitations include the limited applicability to women and other age and ethnic groups, the lack of measurement of ionised calcium and the cross-sectional study setting. Furthermore, on the basis of this study it is not possible to exclude an association between serum calcium and insulin secretion due to the use of EIR rather than the gold standard method for measuring insulin secretion (firstand second-phase insulin levels in the hyperglycaemic insulin clamp). We performed multiple statistical testing and subgroup analyses in relating serum calcium to insulin sensitivity and secretion, but all primary analyses were defined a priori. The consistency of results across different statistical models and subgroups makes it unlikely that the observed association arose by chance due to multiple testing.

\section{Conclusion}

Our data support the notion that endogenous calcium may be involved early in the development of diabetes and that this effect is mediated mainly through effects on insulin sensitivity rather than defective insulin secretion. In contrast, dietary intake of calcium does not seem to influence insulin sensitivity. Further intervention studies are needed in order to establish a causal relationship between serum calcium concentration and insulin sensitivity. 
Acknowledgements This study was supported by Uppsala University, Sweden, Gustaf Adolf Johansson's Foundation, Sweden, Josef and Linnea Carlsson's Foundation, Sweden and Thuréus' Foundation, Sweden.

Duality of interest L. Lind is partially employed by AstraZeneca, Mölndal, Sweden.

\section{References}

1. Ford ES (2005) Risks for all-cause mortality, cardiovascular disease, and diabetes associated with the metabolic syndrome: a summary of the evidence. Diabetes Care 28:1769-1778

2. Sowers JR, Epstein M, Frohlich ED (2001) Diabetes, hypertension, and cardiovascular disease: an update. Hypertension 37:1053-1059

3. Levy J, Stern Z, Gutman A, Naparstek Y, Gavin JR 3rd, Avioli LV (1986) Plasma calcium and phosphate levels in an adult noninsulindependent diabetic population. Calcif Tissue Int 39:316-318

4. Taylor WH, Khaleeli AA (2001) Coincident diabetes mellitus and primary hyperparathyroidism. Diabetes Metab Res Rev 17:175-180

5. Sorva A, Tilvis RS (1990) Low serum ionized to total calcium ratio: association with geriatric diabetes mellitus and with other cardiovascular risk factors? Gerontology 36:212-216

6. Kumar S, Olukoga AO, Gordon C et al (1994) Impaired glucose tolerance and insulin insensitivity in primary hyperparathyroidism. Clin Endocrinol (Oxford) 40:47-53

7. Procopio M, Magro G, Cesario F et al (2002) The oral glucose tolerance test reveals a high frequency of both impaired glucose tolerance and undiagnosed type 2 diabetes mellitus in primary hyperparathyroidism. Diabet Med 19:958-961

8. Levy J (1999) Abnormal cell calcium homeostasis in type 2 diabetes mellitus: a new look on old disease. Endocrine 10:1-6

9. Resnick L (1999) The cellular ionic basis of hypertension and allied clinical conditions. Prog Cardiovasc Dis 42:1-22

10. Wareham NJ, Byrne CD, Carr C, Day NE, Boucher BJ, Hales CN (1997) Glucose intolerance is associated with altered calcium homeostasis: a possible link between increased serum calcium concentration and cardiovascular disease mortality. Metabolism 46:1171-1177

11. Lind L, Jakobsson S, Lithell H, Wengle B, Ljunghall S (1988) Relation of serum calcium concentration to metabolic risk factors for cardiovascular disease. Br Med J 297:960-963

12. Lind L, Skarfors E, Berglund L, Lithell H, Ljunghall S (1997) Serum calcium: a new, independent, prospective risk factor for myocardial infarction in middle-aged men followed for 18 years. J Clin Epidemiol 50:967-973

13. Sun G, Vasdev S, Martin GR, Gadag V, Zhang H (2005) Altered calcium homeostasis is correlated with abnormalities of fasting serum glucose, insulin resistance, and \{beta\}-cell function in the Newfoundland population. Diabetes 54:3336-3339

14. Pittas AG, Dawson-Hughes B, Li T et al (2006) Vitamin D and calcium intake in relation to type 2 diabetes in women. Diabetes Care 29:650-656

15. ULSAM Uppsala Longitudinal Study of Adult Men. Available at $\mathrm{http}: / /$ www.pubcare.uu.se/ULSAM/

16. Ärnlöv J, Lind L, Zethelius B et al (2001) Several factors associated with the insulin resistance syndrome are predictors of left ventricular systolic dysfunction in a male population after 20 years of follow-up. Am Heart J 142:720-724

17. Byberg L, Zethelius B, McKeigue PM, Lithell HO (2001) Changes in physical activity are associated with changes in metabolic cardiovascular risk factors. Diabetologia 44:2134-2139
18. American Diabetes Association (2005) Diagnosis and classification of diabetes mellitus. Diabetes Care 28:S37-S42

19. DeFronzo RA, Tobin JD, Andres R (1979) Glucose clamp technique: a method for quantifying insulin secretion and resistance. Am J Physiol 237:E214-E223

20. Pollare T, Vessby B, Lithell H (1991) Lipoprotein lipase activity in skeletal muscle is related to insulin sensitivity. Arterioscler Thromb 11:1192-1203

21. Andersson PE, Lithell H (1996) Metabolic effects of doxazosin and enalapril in hypertriglyceridemic, hypertensive men. Relationship to changes in skeletal muscle blood flow. Am J Hypertens 9:323-333

22. Haffner SM, Miettinen H, Stern MP (1996) Insulin secretion and resistance in nondiabetic Mexican Americans and non-Hispanic whites with a parental history of diabetes. J Clin Endocrinol Metab 81:1846-1851

23. Haffner SM, Miettinen H, Gaskill SP, Stern MP (1996) Decreased insulin action and insulin secretion predict the development of impaired glucose tolerance. Diabetologia 39:1201-1207

24. Bonadonna RC, Groop L, Kraemer N, Ferrannini E, Del Prato S, DeFronzo RA (1990) Obesity and insulin resistance in humans: a dose-response study. Metab Clin Exp 39:452-459

25. Liu S, Song Y, Ford ES, Manson JE, Buring JE, Ridker PM (2005) Dietary calcium, vitamin D, and the prevalence of metabolic syndrome in middle-aged and older U.S. women. Diabetes Care 28:2926-2932

26. Elders PJ, Lips P, Netelenbos JC et al (1994) Long-term effect of calcium supplementation on bone loss in perimenopausal women. J Bone Miner Res 9:963-970

27. Reid IR, Ames RW, Evans MC, Gamble GD, Sharpe SJ (1993) Effect of calcium supplementation on bone loss in postmenopausal women. N Engl J Med 328:460-464

28. Byyny RL, LoVerde M, Lloyd S, Mitchell W, Draznin B (1992) Cytosolic calcium and insulin resistance in elderly patients with essential hypertension. Am J Hypertens 5:459-464

29. Resnick LM (1993) Ionic basis of hypertension, insulin resistance, vascular disease, and related disorders. The mechanism of "syndrome X". Am J Hypertens 6:123S-134S

30. Begum N, Leitner W, Reusch JE, Sussman KE, Draznin B (1993) GLUT-4 phosphorylation and its intrinsic activity. Mechanism of $\mathrm{Ca}(2+)$-induced inhibition of insulin-stimulated glucose transport. J Biol Chem 268:3352-3356

31. Draznin B, Lewis D, Houlder N et al (1989) Mechanism of insulin resistance induced by sustained levels of cytosolic free calcium in rat adipocytes. Endocrinology 125:2341-2349

32. Åkerström G, Rudberg C, Grimelius L et al (1986) Histologic parathyroid abnormalities in an autopsy series. Human Pathol 17:520-527

33. Fardella C, Rodriguez-Portales JA (1995) Intracellular calcium and blood pressure: comparison between primary hyperparathyroidism and essential hypertension. J Endocrinol Investig 18: $827-832$

34. Borle AB, Uchikawa T (1978) Effects of parathyroid hormone on the distribution and transport of calcium in cultured kidney cells. Endocrinology 102:1725-1732

35. DeFronzo RA, Lang R (1980) Hypophosphatemia and glucose intolerance: evidence for tissue insensitivity to insulin. $\mathrm{N}$ Engl $\mathrm{J}$ Med 303:1259-1263

36. Peacock M, Bilezikian JP, Klassen PS, Guo MD, Turner SA, Shoback D (2005) Cinacalcet hydrochloride maintains long-term normocalcemia in patients with primary hyperparathyroidism. J Clin Endocrinol Metab 90:135-141

37. Shoback DM, Bilezikian JP, Turner SA, McCary LC, Guo MD, Peacock M (2003) The calcimimetic cinacalcet normalizes serum calcium in subjects with primary hyperparathyroidism. J Clin Endocrinol Metab 88:5644-5649 